\title{
Comparison of the efficiency of various flow charts of Longwall coal mining
}

\author{
V. V. OKOLNISHNIKOV \\ Institute of Computational Technologies SB RAS Academician M.A. \\ Lavrentiev avenue, 6, 630090, Novosibirsk RUSSIA
}

\begin{abstract}
For increasing the efficiency of longwall coal mining a mathematical model and a simulation model of the longwall coal mining were developed. 2D and 3D visualizations of the execution of the simulation model were realized. The main goal of the modeling of coal mining in a fully-mechanized stoping face is the comparison of flow charts of Longwall coal mining, the evaluation of performance of a drum shearer depending on such factors as technical parameters of the drum shearer, size of a stoping face, flow charts of the drum shearer operation, changing geomechanical characteristics of the coal seam. As a result of simulation the dependences of the drum shearer performance and annual mine profits on the length of the stoping face and flow charts of the drum shearer operation such as one-way flow chart, shuttle flow chart and bench flow chart were obtained.
\end{abstract}

Key-Words: - simulation, mine, longwall mining, drum shearer, productivity, optimization

Received: July 26, 2019. Revised: December 18, 2019. Accepted: January 14, 2020. Published: January 22, 2020.

\section{Introduction}

At present, many coal mines have problems in making decisions to increase productivity, to improve coal production planning, to use new mining machines and new perspective technologies for coal mining.

Increasing the reliability of information on mining geological conditions of coal seam occurrence and geomechanical characteristics of coal seams is an actual problem for coal mines designing. The initial information for mine designing is based on geological survey data and, due to low network density of prospecting boreholes, it can be insufficient for accurate assessment of commercial reserves of a coal deposit, its geomechanical and geotechnical characteristics. For this reason, in mine operating practice, the cases of considerable deviations from design performance and decline in mine operating efficiency are frequent.

One of the reasons is that in underground coal mining, the dimensions of panel sections increase from year to year and reach $2-3 \mathrm{~km}$ and more, and the distances between prospecting boreholes remain the same and make up $300-500 \mathrm{~m}$. It is impossible to obtain and use reliable parameters of coal seam occurrence and geomechanical characteristics during the design stage at such length of longwalls and wide borehole spacing. Additional rock interlayers and geological faults, changes of dip angle and seam thickness are frequently observed in mine construction and roadway drivage.

Averaging of mining and geological conditions of seam occurrence and seam geomechanical characteristics is usually accepted in mine designing practice. Taking considerable dimensions of panel sections into account, such averaging leads to noncoincidence of design and actual data of coal faces operation and decline in mine operating efficiency. Incorrectness of some existing guidance manuals on advance speed calculation and drum shearer capacity should also be noted.

The goal of this work is the rationale for making decision using mathematical and simulation modeling for increasing the productivity of longwall mining in coal seam with variable geomechanical and geotechnical characteristics.

The originality of this work is the calculation of distributed values of the geomechanical characteristics of the coal seam calculated by the inverse distance weighting method, instead of the average values of the geomechanical characteristics of the coal seam used in practice.

The most suitable way to solve these problems is simulation. There are many publications that support this proposition [1] - [10]. There are also many publications about using simulation to solve problems for longwall coal mining [11] - [16].

To solve these problems for underground coal mines in Kuznetsk Coal Basin (Russia, Western Siberia) the simulation system MTSS [17] was used. It is a visual interactive and process-oriented 
discrete simulation system intended to develop and execute the technological processes models.

The simulation system MTSS was realized in accordance with following requirements:

- Visual interactive interface for simulation models creation and execution.

- Usage of graphical tools for model creation.

- Support for fast model creation.

- Simulation model is created from existing ready-to-use simulation models from subject area oriented libraries.

- Simulation model creation by subject matter experts.

- Simulation model and simulation system must be able to be connected to any external systems.

- Simulation model execute in two-dimension (2D) and three-dimension (3D) views.

- Simulation results are presented as complete analysis, without necessity of any additional analysis.

- Any statistical data can be exported and analyzed externally.

A distinguishing feature of the simulation system is its orientation toward the users who are the experts in a particular subject area (process engineers, mining engineers).

The fast development of models is carried out owing to the visual-interactive interface and specialized libraries of models of technological equipment for specific subject areas, 3D visualization.

To simulate the technological processes in coal mines in MTSS simulation system the specialized libraries of mining machines for such coal mine subsystems as an underground conveyor network, a pumping subsystem, and a power supply subsystem were developed. With the use of the specialized libraries a number of models of these subsystems for underground coal mines in Kuznetsk Coal Basin (Western Siberia) were created [18].

In this paper a new simulation model of longwall coal mining is considered. This model was realized in the frame of the simulation system MTSS with using of a specialized library of models of mining machines in a fully-mechanized stoping face. This model intends to research processes by longwall coal mining and to solve a problem of evaluation the productivity of a drum shearer depending on such factors as technical parameters of the drum shearer, size of a longwall face, flow charts of the drum shearer operation, changing characteristics of the coal seam.
Flow charts of the drum shearer operation such as one-way flow chart, shuttle flow chart and bench flow chart were realized in the simulation model. $2 \mathrm{D}$ and $3 \mathrm{D}$ visualizations of the execution of the simulation model were realized.

The second section of this paper provides a mathematical model of the productivity of the drum shearer. The third section describes the simulation model of the longwall coal mining operation and the results of its implementation and execution.

\section{The mathematical model of productivity of the drum shearer}

In mine design, theoretical advance speed (V) and productivity (A) of a drum shearer in longwall mining is determined from the formulas (1) and (2) $[19,20]$.

$$
V=\frac{30 N \eta n_{1} K_{1}}{f P \cos \alpha \pm P \sin \alpha+S m n_{2} K_{o}(m) K},
$$

where:

$N$ - the capacity of drum shearer drive;

$\eta$ - the efficiency of feed drive gearbox;

$n_{1}$ - the number of picks in a cutting line (assumed subject to the drum design);

$K_{l}$ - the coefficient taking into account a part of capacity of drum shearer drive to move the drum shearer;

$f$ - the coefficient of sliding friction between drum shearer and scraper conveyor;

$P$ - the drum shearer weight;

$\alpha$ - the dip angle of coal seam;

"plus" and "minus" in front of the drum shearer weight specify the drum shearer movement up and down the longwall respectively;

$S$ - the averaged cutting resistance of coal;

$m$ - the mineable thickness of coal seam;

$n_{2}$ - the number of picks that cut coal simultaneously (for most drum shearers, this number includes half of all picks on the drum);

$K_{0}$ - the coefficient, taking into account the decreasing of the cutting resistance of coal under the influence of rock pressure;

$K$ - a certain coefficient taking into account the characteristics of cutting angle as well as width, dulling, and shape of picks.

$$
A=\gamma m r V=\frac{30 \gamma m \tau N \eta n_{1} K_{1}}{f P \cos \alpha \pm P \sin \alpha+S m n_{2} K_{o}(m) K},
$$

where:

$\gamma$ - the coal density;

$r$ - the drum shearer cutting width.

The averaged characteristics of the coal seam are used in formulas (1) and (2). More accurate formulas (3) and (5) are proposed in [21]. The 
averaged characteristics of the coal seam have been replaced by distributed ones. $\mathrm{V}(\mathrm{x}, \mathrm{y}), \mathrm{A}(\mathrm{x}, \mathrm{y}), \alpha(\mathrm{x}, \mathrm{y})$, $\mathrm{S}(\mathrm{x}, \mathrm{y}), \quad \mathrm{m}(\mathrm{x}, \mathrm{y}), \quad \gamma(\mathrm{x}, \mathrm{y})$ are functions of the corresponding characteristics of the coal seam in current position of the drum shearer with $(\mathrm{x}, \mathrm{y})$ coordinates.

$$
\begin{gathered}
V(x, y)=\frac{30 N \eta n_{1} K_{1}}{f P \cos \alpha(x, y) \pm P \sin \alpha(x, y)+\Delta(x, y)} \\
\Delta(x, y)=S(x, y) m(x, y) n_{2} K_{o}(m(x, y)) K \\
A(x, y)=\gamma(x, y) m(x, y) r V(x, y)
\end{gathered}
$$

Values of functions $\alpha(x, y), S(x, y), m(x, y), \gamma(x, y)$ are calculated with the Inverse Distance Weighting method according to the following general function (6).

$$
F(x, y)=\left\{\begin{array}{l}
\frac{\sum_{i=1}^{n} d_{i}^{-2} F_{i}}{\sum_{i=1}^{n} d_{i}^{-2}}, \text { if } d_{i} \neq 0 \\
F_{i}, \text { if } d_{i}=0
\end{array}\right.
$$

where:

$n$ - the number of geological prospecting wells nearest to stoping face that are taken into account while calculating,

$F_{i}$ - values of the corresponding characteristics of the coal seam in $i_{\text {th }}$ geological prospecting well,

$d_{i}$ - the distance between the $i_{t h}$ geological prospecting well and the mining face with current position of the drum shearer $(x, y)$.

\section{The simulation model}

In the frames of simulation system MTSS a complex integrated model of longwall coal mining was implemented. This model involves the following interacting parts: the coal seam model, the drum shearer model, the model of scraper conveyor, and the model of powered roof supports.

The parameters of the coal seam model are:

- The number of geological prospecting wells, their geographical coordinates, and values of coal seam characteristics in each geological prospecting well.

- Thickness of coal seam.

- The length of the longwall face etc.

- The parameters of the drum shearer model are:

- The capacity of drum shearer drive.

- The efficiency of feed drive gearbox.

- The number of picks in a cutting line.

- The weight of drum shearer.

- The coefficient of sliding friction between drum shearer and scraper conveyor etc.
All parameters of the mine equipment models and coal seam model correspond with the parameters of the actual mine equipment operating at one of the coal mine in Kuznetsk Coal Basin. The main goal of the detailed simulation of longwall coal mining is the evaluation of productivity of a drum shearer depending on different factors such as: technical parameters of the drum shearer, size of a longwall face, flow charts of the drum shearer operation, changing geophysical parameters of the coal seam.

Generally the following factors influence the productivity of the drum shearer in the stoping face:

- The geophysical state of the coal seam.

- The advance speed of the drum shearer;

- The technical characteristics of the drum shearer;

- The delays at the end of the longwall face;

- The delays associated with the movement of the roof support;

- The delays associated with the scraper conveyor;

- The delays associated with the belt conveyor;

- The delays associated with the increase of methane release;

- The delays associated with equipment failures;

- Regulations conditions and maintenance etc.

In this paper the influence of the first six factors on the drum shearer productivity was studied.

The main window of the longwall coal mining model carried out with simulation system MTSS is presented in Fig. 1. The right gray field represents a coal seam; the blue rectangles mark the positions of two augers of a drum shearer. The arrow shows the direction of movement of the drum shearer. Black rectangles represent pans filled with coal. Yellow rectangles represent empty pans. The positions of the sections of the mechanized roof supports are indicated by brown rectangles.

Fig. 1 shows a sample of 2D visualization of model execution. Fig. 2 shows a sample of 3D visualization of model execution.

The parameters of mining machines and flow charts of drum shearer operation can be set interactively in the parameters window. The control buttons are located in the main window: to start the drum shearer; to stop the drum shearer.

The main factor influencing on the drum shearer productivity is the state of the coal seam (the coal cutting resistance). It restricts the drum shearer advance speed. 
A feature of the simulation model is a detailed simulation of drum shearer motion, including oblique turning, the interaction of the motion of the drum shearer with other mining machines (powered supports and scraper conveyor), distributed calculation of mining-geological and geomechanical states of the coal seam, as well as gas-bearing capacity based on exploration well data. Simulation experiments using the proposed model provide theoretical and simulation results for comparing and solving optimization problems.

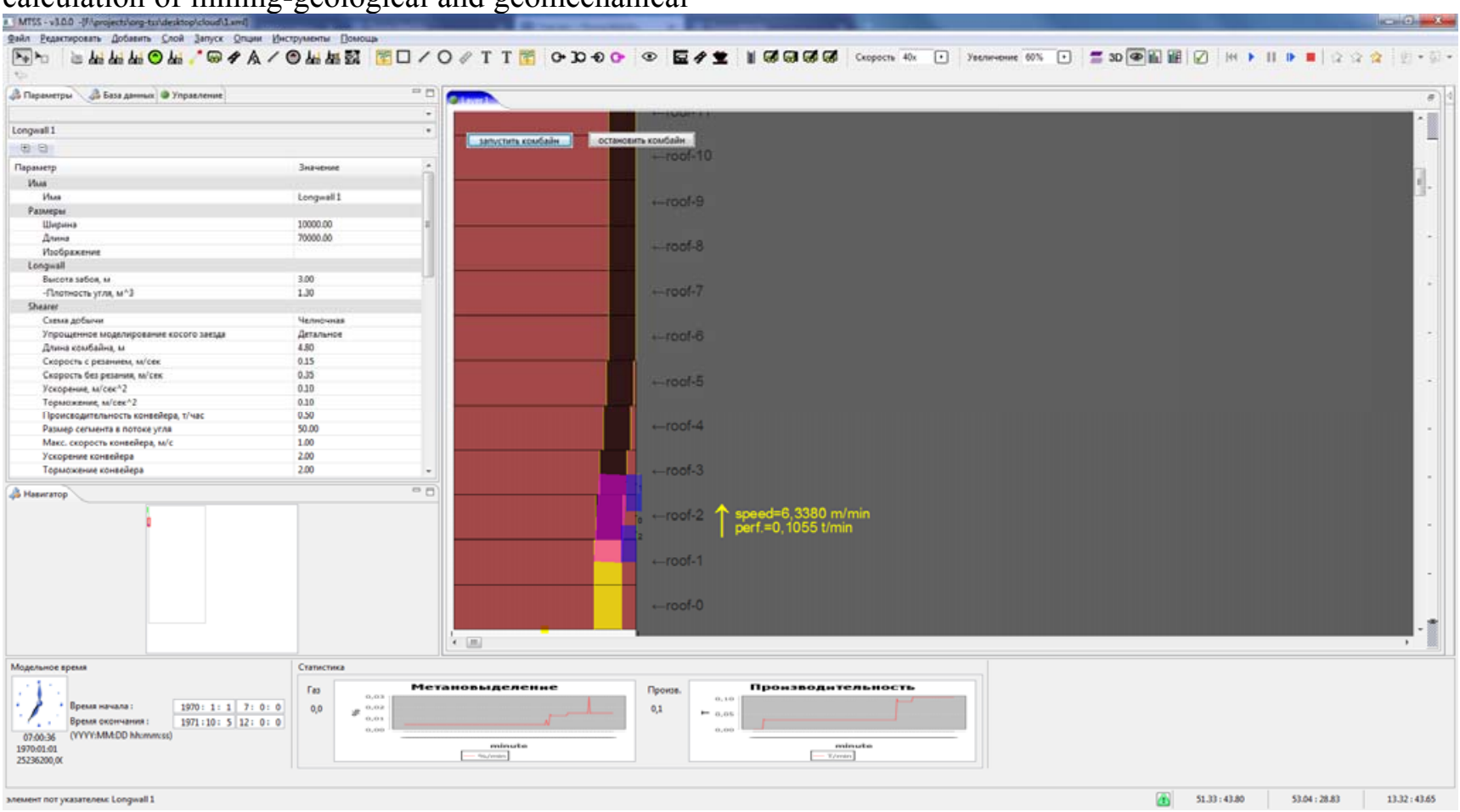

Fig. 1. The main window of the longwall coal mining model.

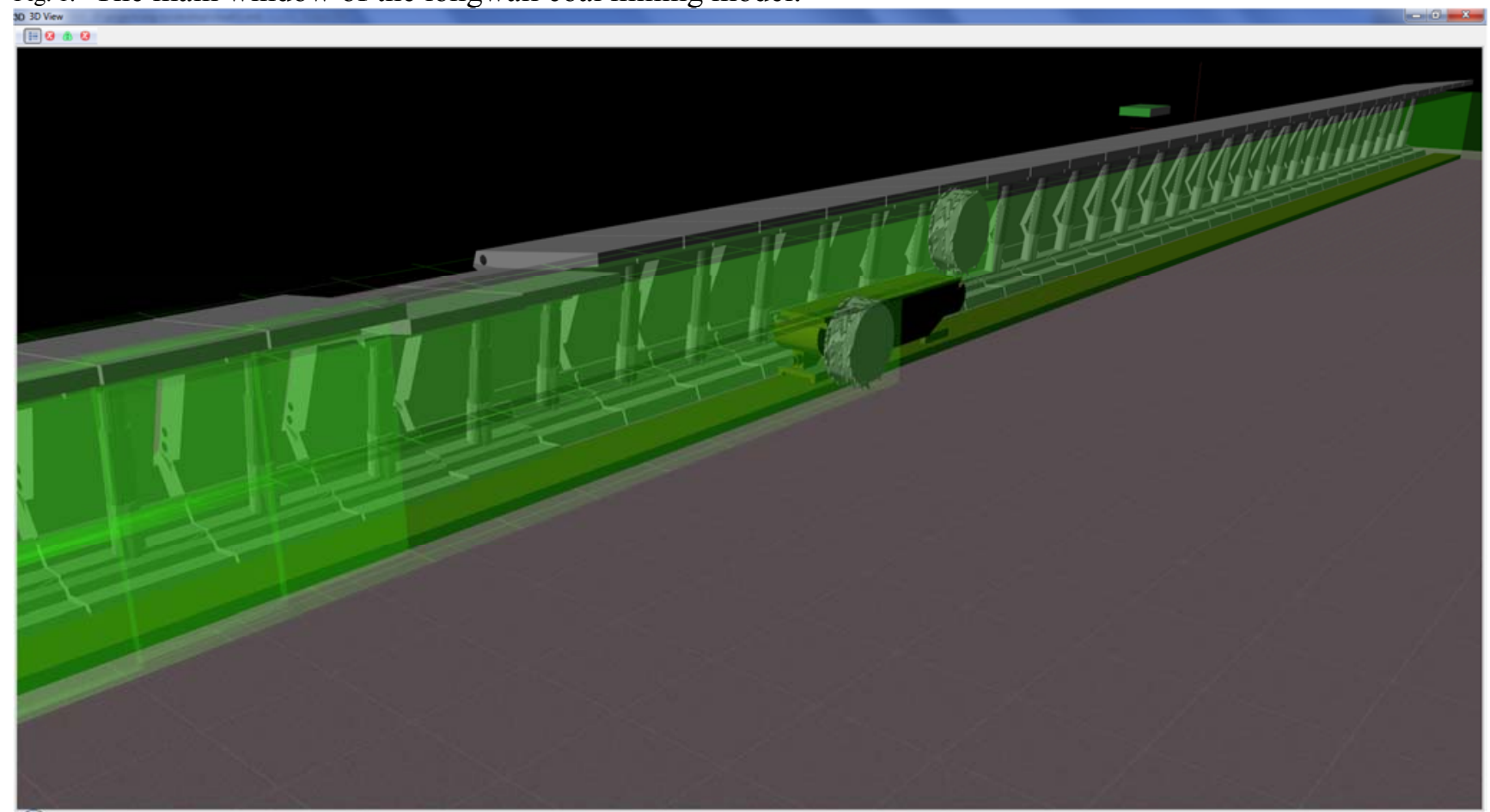

Fig. 2. 3D visualization of model execution.

The MTSS system has a mining machine database containing several dozen items (brands). Once a mining machine is chosen, all its technical characteristics are loaded into the model.
Before running the model, the user selects the mining machines involved in the simulation experiment (shearer, powered roof supports, conveyors) using the menu system. The MTSS 
system has a mining machine database containing several dozen items (brands). Once a mining machine is chosen, all its technical characteristics are loaded into the model.

Next, the user sets the number and coordinates of exploration wells and the mining-geological and geomechanical characteristics of the coal seam in these wells. The database contains information on exploration wells for several Kuznetsk Coal Basin mines.

After that the user sets the linear dimensions of the face, for example the face length, selects flow chart of operation of the drum shearer, sets model run modes and forms of output data presentation, and runs the model.

In longwall mining are applied following flow charts operation of the drum shearer: one-way flow chart, shuttle (two-ways) flow chart and bench flow chart.

In the one-way flow chart the cycle of operation of the drum shearer consists of its forward motion in the operating mode and in the reversely motion in the mode of the cleaning-up. In the shuttle mode the cycle of operation of the drum shearer consists of its forward and reversely motion in the operating mode.

The one-way flow chart and shuttle flow chart are used for coal cutting with respect to complete seam thickness; the upper and lower drums operate simultaneously.

Shuttle or bench flow chart is usually used in mining thick coal seams. When applying the shuttle flow chart, the seam is cut with respect to total thickness by two drums with diagonal entries of the shearer at the end of mining of each coal band. In the bench flow chart, first the upper layer of the seam with the thickness corresponding to the drum diameter is extracted, as the drum shearer moves upward in the longwall, and then the lower seam layer is cut with retreat cleaning-up.

In bench flow chart, first the upper bench with a thickness equal to drum diameter is cut sequentially and then, when drum shearer moves reversely, the remaining lower seam layer is cut. This flow chart is usually applied for coal seams with a thickness of 4-6 m. In bench flow chart coal is extracted by one drum, the upper one in cutting the upper bench and the lower one in extracting the lower bench.

The subject of the research is the detailed simulating of one-way flow chart, shuttle flow chart and bench flow chart of the drum shearer operation together with movement of powered roof supports depending on geophysical state of coal seam.

With the developed longwall mining simulation model a series of experiments was performed. During the run of the simulation model, the current values of all output parameters are calculated. These current values can be displayed in user-specified indicators in the main window of the model or as graphs in the main window of the model or in new windows.

As a result of simulation the dependence of the drum shearer performance on the length of the longwall face and flow charts of the drum shearer operation such as one-way flow chart, shuttle flow chart and bench flow chart was obtained. The obtained results are presented in the form of graphs in Fig. 3 (in tons per minute).

The solid red line in the figure corresponds to the bench flow chart. The blue dotted line in the figure corresponds to the one-way flow chart. The green dash-dot line in the figure corresponds to the shuttle flow chart.

The productivity of the drum shearer was calculated with using (5). All experiments were carried out under the equal conditions of the movement of the drum shearer SL-500/1 to a certain depth into the coal seam in Ilevsky Mine in Kuznetsk Coal Basin.

The obtained results allow us to conclude the following:

- The shuttle flow chart of coal mining is more productive then other flow charts.

- Increasing the length of the longwall face, beginning from a certain value, does not significantly affect the increase in the productivity of the drum shearer.

Using the results of simulation the productivity of drum shearer, the dependence of the annual stoping face profit on the length of the face and flow charts of coal mining was obtained. The obtained results are presented in the form of graphs in Fig. 4 (in million RUR per year).

The solid red line in the figure corresponds to the bench flow chart. The blue dotted line in the figure corresponds to the one-way flow chart. The green dash-dot line in the figure corresponds to the shuttle flow chart. 


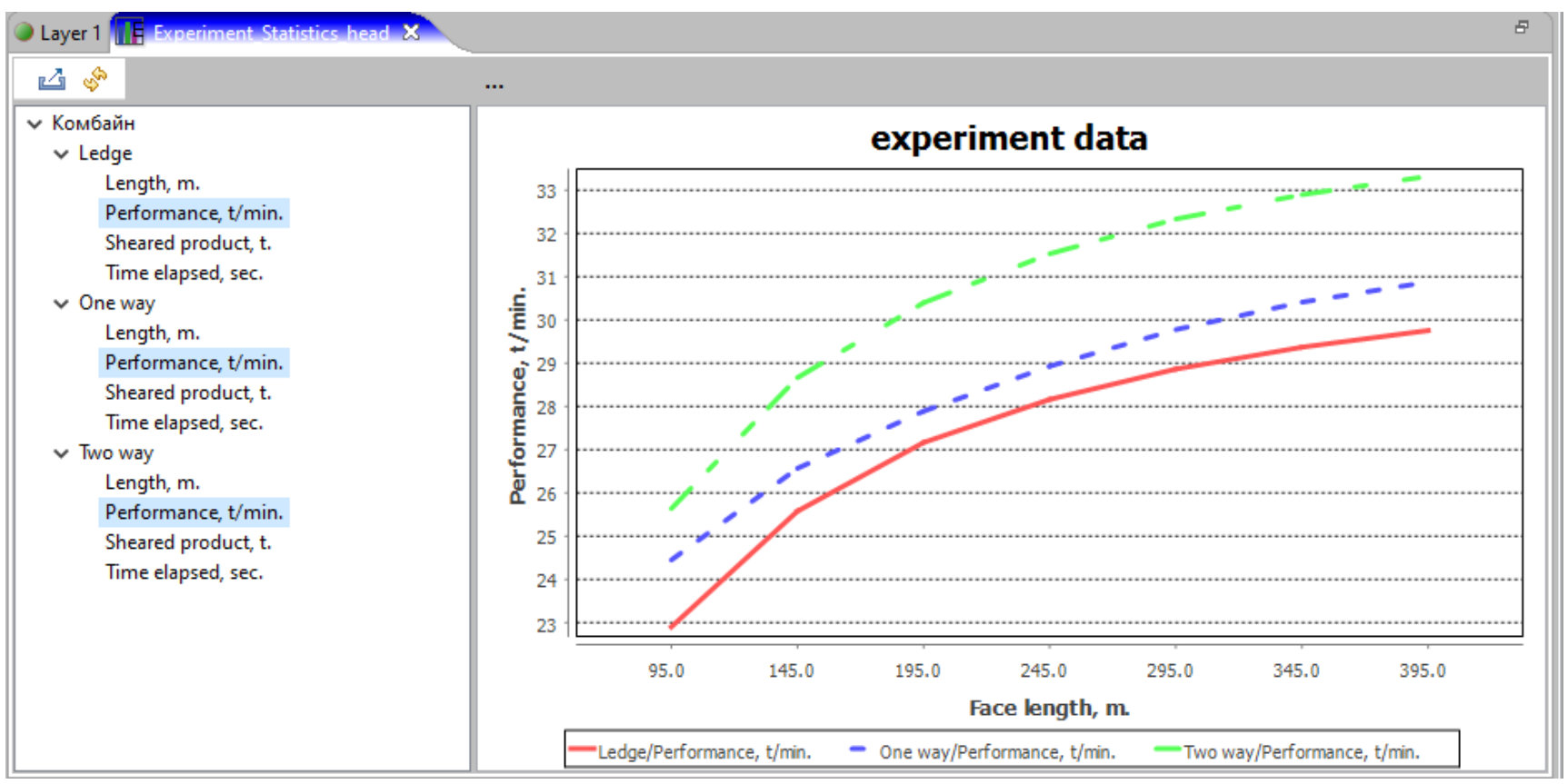

Fig. 3. The dependence of the drum shearer performance on the length of longwall face and flow charts of the drum shearer operation.

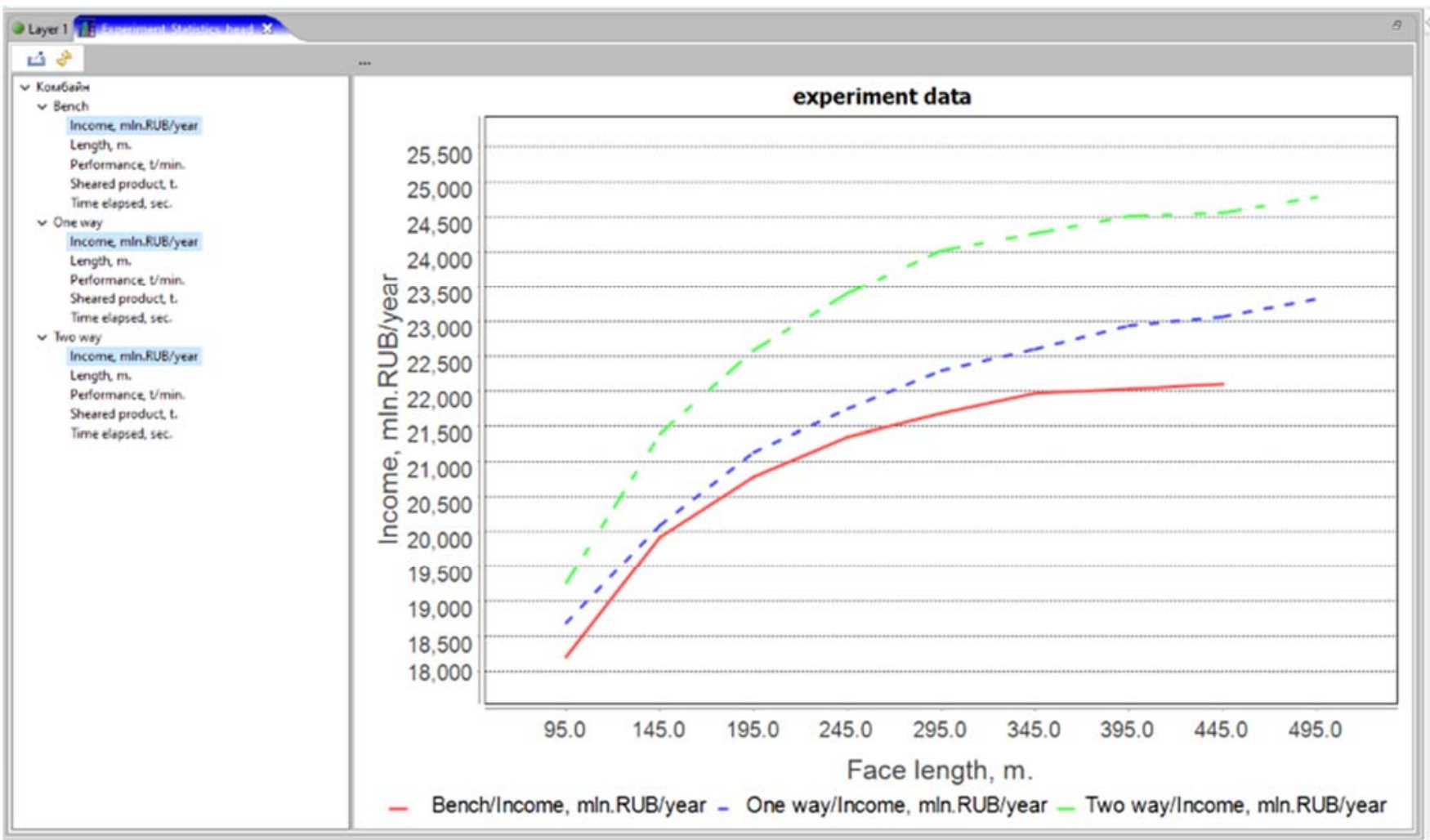

Fig. 4. The dependence of annual stoping face profits on the length of longwall face and flow charts of the drum shearer operation.

The annual profit was calculated as the annual profit received by the mine from the sale of coal from the face, minus the annual operating costs. The annual operating costs consist of two parts. The first part is fixed costs (without amortization) in the face for salaries, materials, electricity etc. regardless of the length of the face. The second part is operating costs depending on the length of the face.
When calculating the annual profit the operation of the face in the mode of two working shifts and one maintenance shift per day was taken into account. Some other relevant studies can be found in [22] and [23]. 


\section{Conclusion}

A MTSS model has been developed for a longwall mining operation. The model is capable of simulating all longwall cutting operations and has the ability to assess the impact of operational parameters and delays on coal production. A distinctive feature of the model is the calculation of the distributed values of geomechanical characteristics of the coal seam, in contrast used in practice to the average values of the ones. The model can be used to help practitioners determine how can be achieved the increasing the productivity of coal mining by changing various operational parameters before costly tests are undertaken. The extension of the considered model of the stoping face operation is assumed to be carried out in the future. Models of aerogasdynamics of methane-air flow in a long stope and models of a belt conveyors subsystem, a ventilating subsystem, and a power supply subsystem of a coal mine will be additionally included into the complex model of the stoping face operation. The MTSS simulation system can be used not only for simulation of the existing coal mining technologies, but also for simulation of perspective robotized technologies and manless coal mining technologies.

\section{References:}

[1] J. Greberg, F. Sundqvist, Simulation as a tool for mine planning, Proc. 2th International Future Mining Conference, Sydney, New South Wales, 2011, pp. 273-278.

[2] A. Salama, J. Greberg, H. Schunnesson, The use of discrete event simulation for underground haulage mining equipment selection, International Journal of Mining and Mineral Engineering, Vol.5, No.3, 2014, pp. 256-271.

[3] M. Fioroni, L. Santos, L. Franzese, I. Santana, G. Telles, J. Seixas, B. Penna, and G. Alkmim, Logistic Evaluation of an Underground mine Using Simulation, Proc. Winter Simulation Conference, Savannah, GA, USA, 2014, pp. 1855-1865.

[4] T. N. Michalakopoulos, C. P. Roumpos, M. J. Galetakis, and G. N. Panagiotou, DiscreteEvent Simulation of Continuous Mining Systems in Multi-layer Lignite Deposits, Proc. 12th International Symposium Continuous Surface Mining, 2015, pp. 225-239.
[5] P. Gospodarczyk, Modeling and Simulation of Coal Loading by Cutting Drum in Flat Seams, Archives of Mining Sciences, Vol.61, No.2, 2016, pp. 385-379.

[6] S. Que, K. Awuah-Offei, and S. Frimpong, Optimising design parameters of continuous mining transport systems using discrete event simulation, International Journal of Mining, Reclamation and Environment, Vol.30, No.3, 2016, pp. 217-230.

[7] A. Anani, K. Awuah-Offei, and J. Hirschi, Application of discrete event simulation in optimising coal mine room-and-pillar panel width: a case study, Transactions of the Institution of Mining and Metallurgy, Section A: Mining Technology, Vol. 126, No.1, 2016, pp. 1-9.

[8] Xuefeng Li, Shibo Wang, Reza Malekian, Shangqing Hao, and Zhixiong Li, Numerical Simulation of Rock Breakage Modes under Confining Pressures in Deep Mining: An Experimental Investigation, IEEE Access, Vol.4, 2016, pp. 5710-5720.

[9] V N Fryanov, L D Pavlova, and M V Temlyantsev, Theoretical approaches to creation of robotic coal mines based on the synthesis of simulation technologies, IOP Conf. Series: Earth and Environmental Science, Vol.84, 2017, pp. 1-7.

[10] Jinxia Liu, Chao Ma, Qingliang Zeng, and Kuidong Gao, Discrete Element Simulation of Conical Pick's Coal Cutting Process under Different Cutting Parameters, Shock and Vibration, Hindawi, Vol.2018, 2018, pp. 1-9.

[11] R. Dimitrakopoulos, and S. X. Li Quantification of fault uncertainty and risk assessment in longwall coal mining: stochastic simulation, back analysis, longwall design and reserve risk assessment, Transactions of the Institution of Mining and Metallurgy, Section A: Mining Technology, Vol.119, No.2, 2010, pp. 59-67.

[12] M. S. Kizil, A. McAllister, and R. Pascoe, Simulation of Development in Longwall Coal Mines, Proc. 11th Underground Coal Operators' Conference, University of Wollongong \& the Australasian Institute of Mining and Metallurgy, 2011, pp. 91-98.

[13] D. Cai, E. Baafi, and I. Porter, Modelling a longwall production system using flexsim 3D simulation software, Proc. Twenty first international symposium on Mine planning and equipment selection, New Delhi, India, 2012, pp. 107-114. 
[14] Yubing Gao, Dongqiao Liu, Xingyu Zhang, and Manchao He, Analysis and Optimization of Entry Stability in Underground Longwall Mining, Sustainability, Vol.9, No.11, 2017, pp. 2079-2088.

[15] Ryszard Snopkowski, Aneta Napieraj, and Marta Sukiennik, Method of the Assessment of the Influence of Longwall Effective Working Time Onto Obtained Mining Output, Archives of Mining Sciences, Vol.61, No.4, 2017, pp. 967-977.

[16] Samar S. Ahmed, Marwan AlHeib, Yann Gunzburger, and Vincent Renaud, 3D Numerical Simulation of the Goaf Due to Large-Scale Longwall Mining, Proc. International Congress and Exhibition "Sustainable Civil Infrastructures: Innovative Infrastructure Geotechnology", 2018, pp. 121131.

[17] V. V. Okolnishnikov, S. V. Rudometov, A System for Computer Simulation of Technological Processes, St. Petersburg State Polytechnic University Journal. Computer Science. Telecommunications and Control Systems, Vol.181, No.1, 2014, pp. 62-68.

[18] V. Okolnishnikov, S. Rudometov, and S. Zhuravlev, Simulating the Various Subsystems of a Coal Mine, Engineering, Technology \& Applied Science Research, Vol.6, No.3, 2016, pp. 993-999.

[19] A. A. Ordin, A. A. Metel'kov, Analysis of longwall face output in screw-type cutterloader-and-scraper conveyor system in underground mining of flat-lying coal beds, Journal of Mining Science, Vol.51, No.6, 2015, pp. 1173-1179.

[20] A. A. Ordin, A. M. Nikol'sky, Optimizing Cutting Width and Capacity of Shearer Loaders in Longwall Mining of Gently Dipping Coal Seams, Journal of Mining Science, Vol.54, No.1, 2018, pp. 69-76.

[21] A. A. Ordin, V. V. Okolnishnikov, S. V. Rudometov, and A. A. Metel'kov, Evaluation of Drum Shearer Capacity in Coal Seam with Variable Geomechanical and Geotechnical Characteristics, Journal of Mining Science, Vol.55, No.1, 2019, pp. 57-65.

[22] Victor Kasyanov, Elena Kasyanova, Timur Zolotuhin, Visualization of Graph Representations of Data-Flow Programs, WSEAS Transactions on Information Science and Applications, pp140-146, Volume 15, 2018

[23] Erik F Méndez, José Herrera, Gabriela Mafla, Automatic model based on Artificial Neural Networks to predict the emissions of Carbon
Dioxide (CO2), WSEAS Transactions on Systems, pp.245-252, Volume 18, 2019 